\title{
Axillary artery cannulation for extracorporeal membrane oxygenator support in adults: An approach to minimize complications
}

Nader Moazami, MD, Marc R. Moon, MD, Jennifer S. Lawton, MD, Marci Bailey, RN, and Ralph Damiano, Jr, MD, St Louis, Mo

$\mathrm{E}$ xtracorporeal membrane oxygenation (ECMO) has been used for cardiac and pulmonary support in the adult population and as a bridge to transplantation. ${ }^{1,2}$ One of the unique advantages of ECMO is that support can be established through peripheral access with the chest closed.

The most common route for peripheral cannulation involves the common femoral artery and vein. Direct cannulation of the femoral artery risks injury to the artery, compromises blood flow to the leg, and is the most common cause of limb complications. In addition, blood flow to the heart and brain is mostly retrograde. This report summarizes our approach for using the axillary artery.

\section{Technique}

Venous cannulation is achieved through the right common femoral vein. The axillary artery is exposed through a right subclavicular incision and mobilized circumferentially. After administering 5000 units of heparin, a 1-cm arteriotomy is created, and an 8-mm Gelsoft Plus graft (Sulzer Vascutek, Austin, Tex) is sewn onto the artery in an end-to-side fashion (Figure 1). The anastomosis and the graft can then be reinforced with application of BioGlue Surgical Adhesive (CryoLife, Kennesaw, Ga).

A $24 \mathrm{~F}$ arterial cannula (Edwards Lifesciences LLC, Irvine, Calif) is placed through the externalized graft and directed to within $1 \mathrm{~cm}$ of the anastomosis. The graft is secured to the cannula by tying umbilical tapes along its length (Figure 2). The circuit is secured to the patient by placing additional heavy sutures.

At the time of device removal, decannulation is easy and can even be performed by the bedside if necessary. The arterial cannula is removed, and the Dacron graft is cut, leaving a 0.5to $1-\mathrm{cm}$ chimney cuff. The cuff can either be stapled or oversewn. The venous cannula is simply removed, and the purse string is tied.

\section{Discussion}

We have currently used this technique in 5 patients. One patient needed ECMO support after lung transplantation because of he-

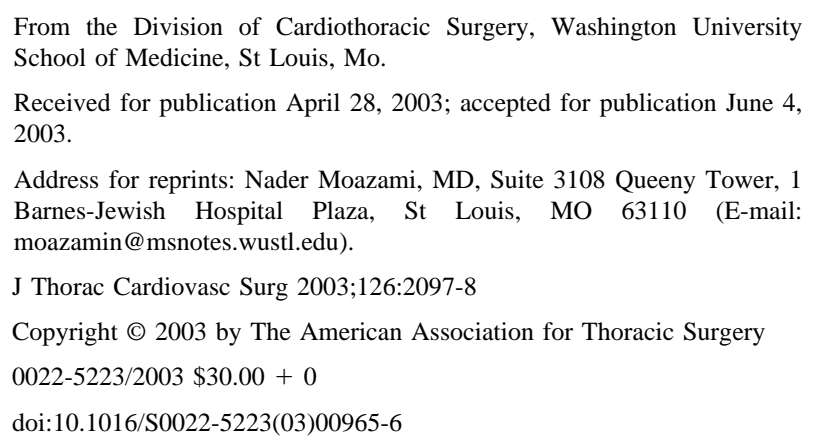

From the Division of Cardiothoracic Surgery, Washington University School of Medicine, St Louis, Mo.

Received for publication April 28, 2003; accepted for publication June 4, 2003.

Address for reprints: Nader Moazami, MD, Suite 3108 Queeny Tower, 1 Barnes-Jewish Hospital Plaza, St Louis, MO 63110 (E-mail: moazamin@msnotes.wustl.edu).

J Thorac Cardiovasc Surg 2003;126:2097-8

Copyright (C) 2003 by The American Association for Thoracic Surgery $0022-5223 / 2003 \$ 30.00+0$

doi:10.1016/S0022-5223(03)00965-6

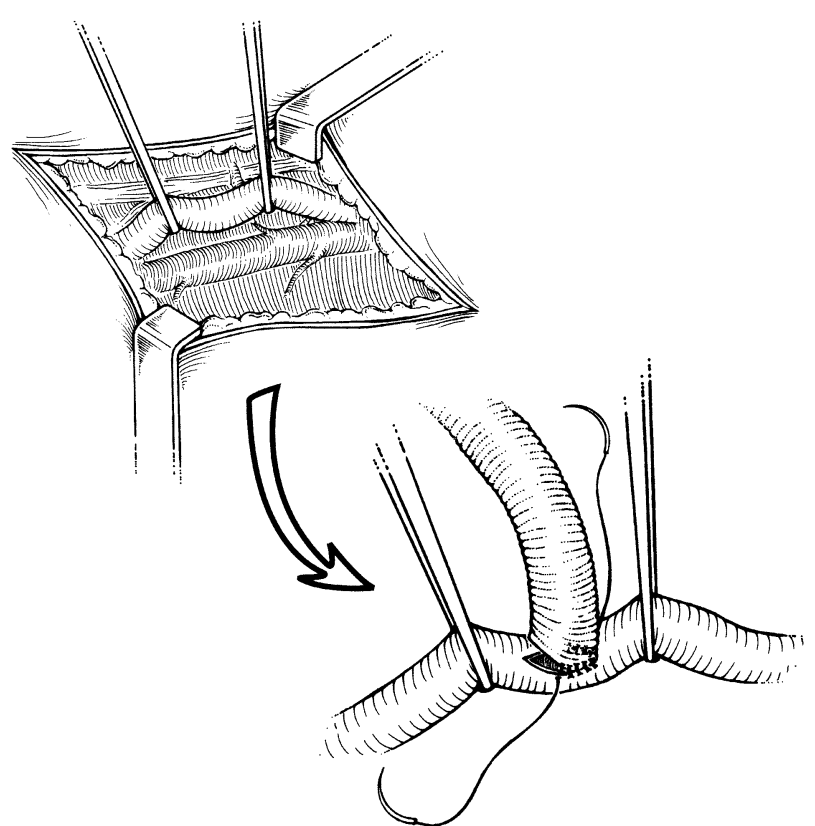

Figure 1

modynamic instability and poor oxygenation related to early graft dysfunction from reperfusion injury. This patient was supported for 7 days, successfully weaned, and discharged. Another patient was transferred to our institution in shock after acute left main coronary artery occlusion and required rapid institution of circulatory support. After 3 days of support, he remained stable, but a planned bridge to a chronic left ventricular assist device was abandoned after the family decided to withdraw support. The other 3 patients required support because of postcardiotomy cardiogenic shock. One patient was successfully weaned and survived to discharge, and in the other 2 patients, support was terminated because of failure to wean. Patients were supported on ECMO for a median of 3 days (range, 2-7 days). Flow was in the range of 3.5 to $5 \mathrm{~L} / \mathrm{min}$. In all cases flow was adequate, with reversal of end-organ dysfunction and no evidence of metabolic acidosis. There was no evidence of wound complications or infections related to the exposed graft. There was no incidence of limb complications. In addition, we had excellent hemostasis, and none of the patients required return to the operating room for bleeding complications.

The technique described has been previously used to establish cardiopulmonary bypass access for treatment of ascending aortic aneurysm. ${ }^{3}$ Long-term use of this approach has not been previously reported. Dissection and cannulation of the axillary artery through a side graft is a simple procedure, and the 


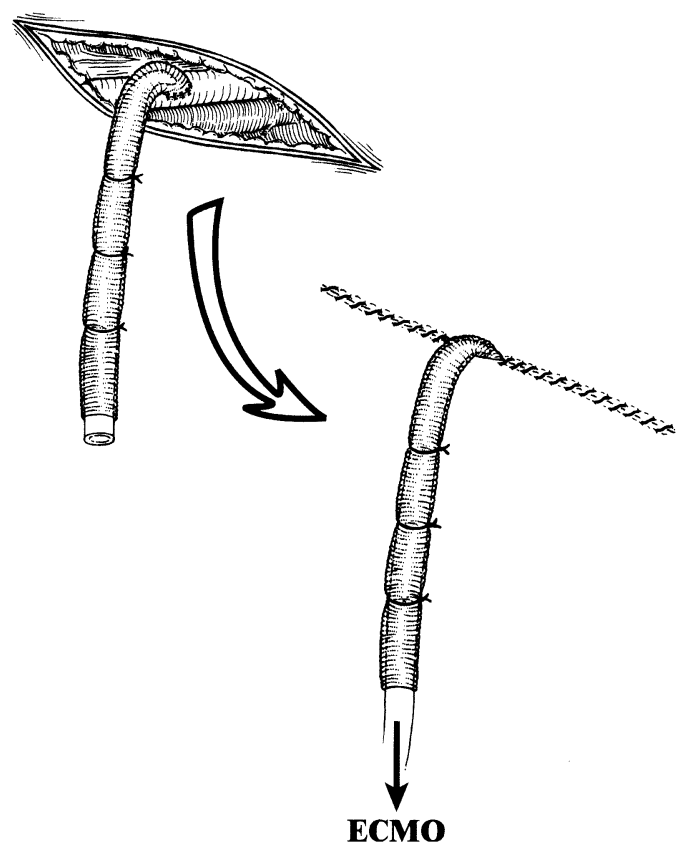

Figure 2

axillary artery is usually free of atherosclerotic disease. This approach maintains perfusion to the extremities and provides antegrade blood flow directly to the ascending aorta. Oxygenated blood is delivered to the brain and the coronary arteries, where it is needed the most.

Another unique advantage is the ability to close the chest, which minimizes the risk of mediastinitis and also decreases ongoing hemorrhage from the sternal edges. In case of bleeding complications at the cannulation sites, local wound exploration can easily be performed at the bedside.

We have now used this method in 5 patients, with no complications related to the technique of cannulation. This remains our preferred approach for ECMO support. In cases in which there is excessive chest wall edema or in morbidly obese patients in whom dissection of the axillary artery might be problematic, the same technique can be applied to the common femoral artery.

\section{References}

1. Smedira NG, Moazami N, Golding CM, McCarthy PM, AppersonHansen C, Blackstone EH, et al. Clinical experience with 202 adults receiving extracorporeal membrane oxygenation for cardiac failure: survival at five years. $J$ Thorac Cardiovasc Surg. 2001;122:92-102.

2. Pagani FD, Aaronson KD, Swaniker F, Bartlett RH. The use of extracorporeal life support in adult patients with primary cardiac failure as a bridge to implantable left ventricular assist device. Ann Thorac Surg. 2001;71(suppl 3):77-85.

3. Sabik JF, Lytle BW, McCarthy PM, Cosgrove DM. Axillary artery: an alternative site of arterial cannulation for patients with extensive aortic and peripheral vascular disease. J Thorac Cardiovasc Surg. 1995;109: $885-91$.

\title{
Left-sided cervical aortic arch aneurysm: Case report
}

\author{
Kazuhiko Higuchi, MD, ${ }^{a}$ Kenzi Koseni, MD, ${ }^{a}$ and Shinichi Takamoto, MD, ${ }^{b}$ Chiba and Tokyo, Japan
}

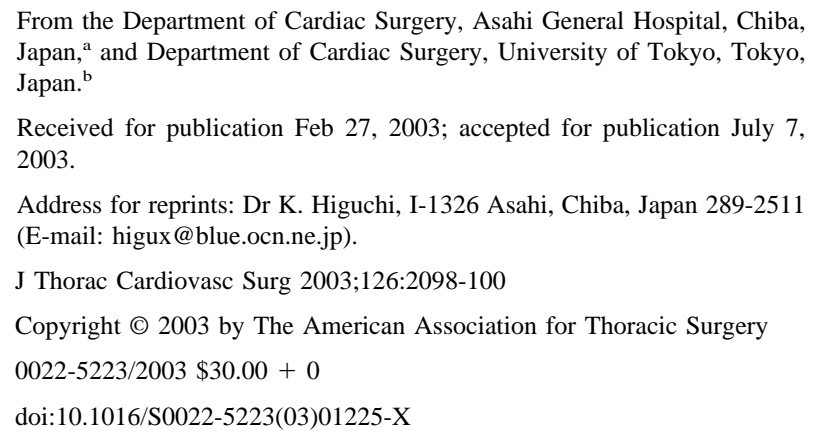

From the Department of Cardiac Surgery, Asahi General Hospital, Chiba, Japan, $^{\mathrm{a}}$ and Department of Cardiac Surgery, University of Tokyo, Tokyo, Japan. $^{\text {b }}$

Received for publication Feb 27, 2003; accepted for publication July 7, 2003.

Address for reprints: Dr K. Higuchi, I-1326 Asahi, Chiba, Japan 289-2511 (E-mail: higux@blue.ocn.ne.jp).

J Thorac Cardiovasc Surg 2003;126:2098-100

Copyright $\odot 2003$ by The American Association for Thoracic Surgery $0022-5223 / 2003 \$ 30.00+0$

doi:10.1016/S0022-5223(03)01225-X

pathologic findings in surgical series support the indication for surgical intervention. ${ }^{2}$

\section{Clinical Summary}

A 16-year-old woman was admitted to Asahi General Hospital with a pulsatile mass in the left neck. Blood pressure was 110/60 $\mathrm{mm} \mathrm{Hg}$ in the right arm and 90/60 $\mathrm{mm} \mathrm{Hg}$ in the left arm. Examination of the neck revealed a visible 4-cm pulsatile mass in the left supraclavicular region. A thrill with a grade II/VI bruit was noted over the left carotid artery. Chest radiography revealed a smooth left-sided mediastinal mass. Three-dimensional computed tomography (3D-CT), magnetic resonance angiography (MRA), and aortography revealed a saccular aneurysm of the cervical aortic arch just distal to the origin of the left carotid artery, with normal branching. An aberrant and torturous left subclavian artery originated from the distal end of the aneurysm (Figure 1).

\section{Surgical Technique}

The aortic arch, the descending aorta, and the left subclavian artery were accessed via a left thoracotomy in the fourth intercostal space. The left superior vena cava was dissected from the aneu- 